\title{
Hearne leads MRS Board of Directors for 2018
}

\section{www.mrs.org/board}

$\mathrm{O}$ January 1, Sean J. Hearne (Sandia National Laboratories) assumed the presidency of the Materials Research Society (MRS) for 2018, after serving as vice president/president-elect for 2017. He succeeded Susan Trolier-McKinstry (The Pennsylvania State University), who now serves MRS as immediate past president.

In last fall's annual election of officers and directors, Michael R. Fitzsimmons (Oak Ridge National Laboratory) was elected vice president/president-elect. Eric A. Stach (University of Pennsylvania) continues his term as MRS secretary and David J. Parrillo (The Dow Chemical Company) continues his term as MRS treasurer. MRS Executive Director Todd M. Osman serves as an ex-officio member of the MRS Board of Directors and is the chief staff officer.

Newly elected members to the MRS Board of Directors-Griselda Bonilla, IBM T.J. Watson Research Center; Paul McIntyre, Stanford University; Christopher A. Schuh, Massachusetts Institute of Technology; Rachel Segalman, University of California, Santa Barbara; and Ehrenfried Zschech, Fraunhofer Institute for Ceramic Technologies and Systems - join continuing Board members Li-Chyong Chen, National Taiwan University; Matt Copel, IBM T.J. Watson Research Center; Paul S. Drzaic, Apple, Inc.; Dawnielle FarrarGaines, Johns Hopkins University; Yury Gogotsi, Drexel University; Claudia Gutiérrez-Wing, Instituto Nacional de Investigaciones Nucleares; Young-Chang Joo, Seoul National University; Lincoln J. Lauhon, Northwestern University; Magaly Spector, The University of Texas at Dallas; and Molly M. Stevens, Imperial College London. All members of the Board serve on at least one of the Board's committees: Audit, External Relations, Finance, Governance, Nominating, Operational and Strategic Oversight, and Planning.

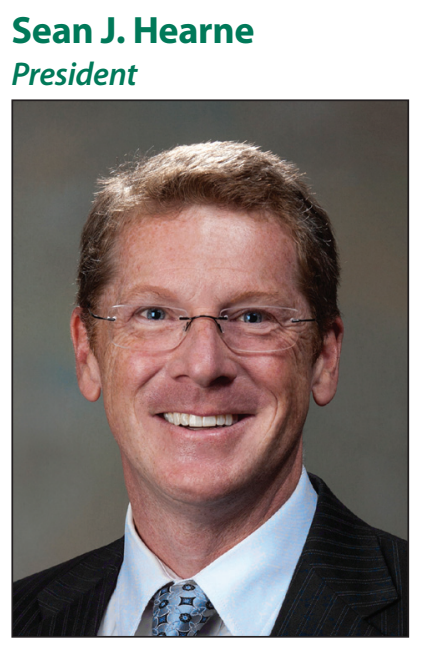

Sean J. Hearne is interim co-director at the US Department of Energy Center for Integrated Nanotechnologies (CINT) located at Sandia National Laboratories, where he works closely with partners from Los Alamos National Laboratory to ensure CINT has a vibrant international user program that advances the understanding of the fundamental science behind integrating nanocomponents into systems that impact the macroscopic world. He received his $\mathrm{PhD}$ degree in solid-state physics from Arizona State University in 2000 . He worked from 2000 to 2001 at Intel Corporation, where he was a senior process engineer in the Components Research Group. Since 2001, Hearne has worked for Sandia National Laboratories in the Physical, Chemical, and Nano Sciences Center, where he has continued his research in the mechanical properties of materials, materials processing, electrical energy storage, and nanotechnology. His research has primarily focused on the sources of intrinsic stress creation and evolution during thin-film deposition, and has been well cited in the area of metal-organic chemical vapor deposition growth of $\mathrm{GaN}$ and in the fundamental mechanisms inducing stress during Volmer-Weber thin-film growth. This work led him into other research topics, including micro- and nanofabrication and nano-enabled devices for electrical energy storage. Hearne has been active in the MRS community since attending his first MRS Meeting in 1995 as a graduate student. Over the years, he has presented, organized symposia, and served on a number of committees and task forces. From 2007 to 2010, he chaired the MRS Information Services Committee, which oversaw all MRS publications. He was secretary on the MRS Board of Directors from 2011 to 2016.

\section{Michael R. Fitzsimmons Vice President/President-Elect}

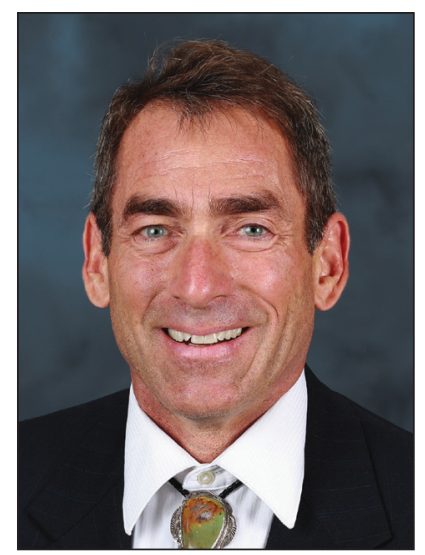

Michael R. Fitzsimmons is group leader for Large Scale Structures in the Neutron Scattering Division at Oak Ridge National Laboratory. He also holds a joint faculty position as professor of physics at The University of Tennessee, Knoxville. He is a Fellow of the American Physical Society and the Neutron Scattering Society of America. Fitzsimmons obtained a BA degree in physics at Reed College and a $\mathrm{PhD}$ degree in materials science and engineering from Cornell University. In 1989 and 1990, Fitzsimmons was a Fulbright Junior Research Fellow at the Ludwig-Maximilians-Universität München, Germany. Prior to moving to Tennessee, he worked at the Los Alamos National Laboratory for 25 years as a research scientist in the fields of magnetism and neutron scattering. While in Tennessee, he developed means to control magnetism of interfaces in heterostructures and vertical-architecture-networked materials using strain and electric fields. Fitzsimmons is developing neutron science 
programs in order to map turbulent flow about objects in cryogenic helium at extreme Reynolds numbers and in order to monitor electric field-assisted sintering of ceramics, and also applications of polarized neutron beams in order to observe atomic and spin fluctuations in soft and hard matter. He has a long history with MRS, including service as a symposium organizer and as a Meeting chair of the 2008 MRS Fall Meeting. He served six years beginning in 2010 as MRS treasurer. During this period, MRS undertook substantive changes to financial governance.

\section{Susan Trolier-McKinstry Immediate Past President}

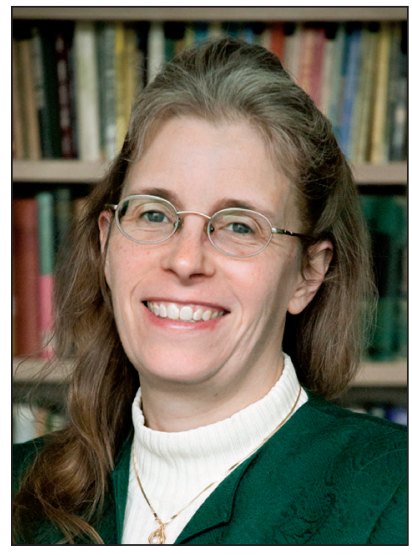

Susan Trolier-McKinstry is the Steward S. Flaschen Professor of Ceramic Science and Engineering and professor of electrical engineering at The Pennsylvania State University (Penn State). She is also director of the nanofabrication facility and co-director of the Center for Dielectric and Piezoelectric Studies. She received her $\mathrm{PhD}$ degree in ceramic science from Penn State in 1992 and has been a member of the faculty since then. Her research group has authored more than 400 papers and holds numerous patents. Group research spans from probing the fundamental mechanisms that contribute to the dielectric and piezoelectric properties of thin films, to processing studies on the deposition and patterning of complex oxides, to integration of functional films into micro-electromechanical systems. She also greatly enjoys teaching, and has mentored more than 50 graduate students. She is an associate editor of Applied Physics Letters; a Fellow of MRS, IEEE, and The American Ceramic Society; and an academician in the World Academy of Ceramics. She has previously served as the president of the IEEE Ultrasonics, Ferroelectrics, and Frequency Control Society, as well as Keramos and the Ceramic Education Council. TrolierMcKinstry has actively participated in MRS since graduate school. She has coorganized numerous symposia, and served as a Meeting chair for the 2003 MRS Fall Meeting. Subsequently, she served on the Program Development Subcommittee until serving a term on the MRS Board of Directors. During that time, she served as the chair of the Strategic Planning Committee.

\section{Eric A. Stach}

Secretary

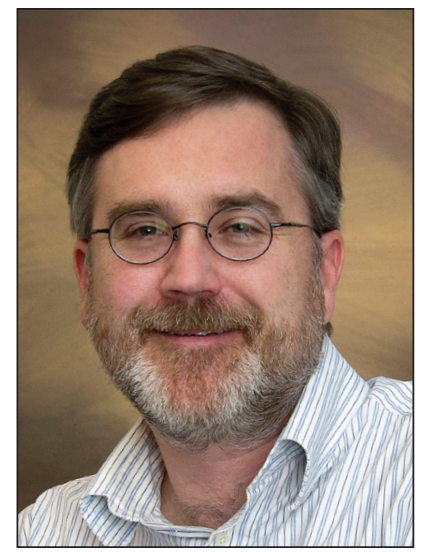

Eric A. Stach is a professor in the Department of Materials Science and Engineering at the University of Pennsylvania. He received his $\mathrm{PhD}$ degree in materials science and engineering from the University of Virginia in 1998. He then joined the National Center for Electron Microscopy at the Lawrence Berkeley National Laboratory as a staff scientist and became the program leader for the metals program in 2003. In 2004, he moved to the School of Materials Engineering at Purdue University as an associate professor and as scientific director for the Birck Nanotechnology Center's electron microscopy lab. At Purdue, he was recognized with undergraduate teaching and early career research excellence awards, by appointment as a university faculty scholar, and promotion to full professor in 2010 . He then returned to the national laboratories in 2010 as group leader at the Center for Functional Nanomaterials at Brookhaven National Laboratory. Stach's research efforts focus on the development and application of electron microscopy techniques in a broad class of materials research, with the common approach being the exploitation of real-time imaging methods to provide quantitative data regarding materials phenomena. He has organized a number of symposia and served as a Meeting chair for the 2012 MRS Fall Meeting. He served on the MRS Board of Directors from 2013 to 2015.

\section{David J. Parrillo}

Treasurer

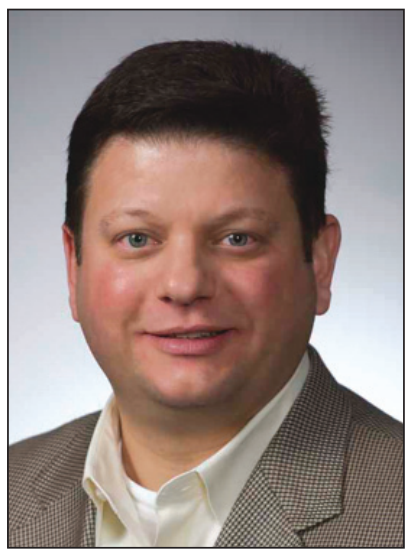

David J. Parrillo is the Global Research and Development Director for Dow Packaging and Specialty Plastics at The Dow Chemical Company. He has experience in materials science research and development, application development, new business development, and adhesives. He holds a BS degree in chemical engineering from the University of Rhode Island and $\mathrm{ahD}$ degree in chemical engineering from the University of Pennsylvania. Previously, he held positions at General Electric (Silicone \& Plastic Business Units) and Air Products and Chemicals. Parrillo serves on the External Advisory Board at the University of California, Santa Barbara, for chemical engineering, and on the Board of Directors for the West Midland Family Center. He also serves as a member of the Leadership Council of Manufacturing Foresight. He holds 15 US patents and has (co-)authored 20 scientific publications. 


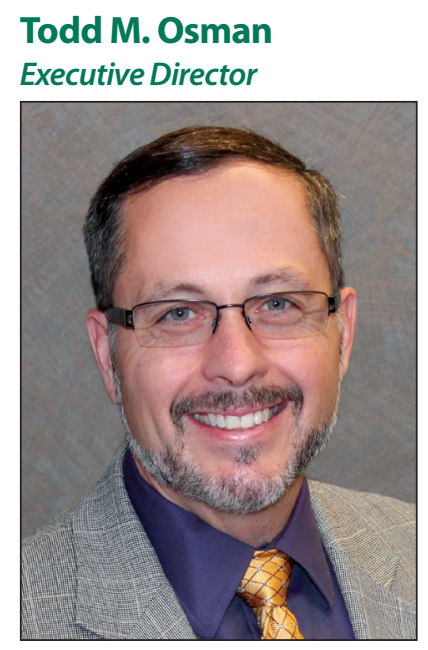

Todd M. Osman became Executive Director of MRS in September 2008. During his tenure, MRS has launched the Materials Research Society Foundation, expanded its communications and meetings portfolio, and broadened its outreach and engagement programs. Prior to joining MRS, Osman co-founded The Pennsylvania NanoMaterials Commercialization Center. He also spent 11 years at the US Steel Corporation, where he received peer and corporate recognition for his research and coordinated cooperative R\&D programs in North America, Europe, and Asia. He received his $\mathrm{PhD}$ degree in materials science and engineering from Case Western Reserve University and has authored numerous articles. Osman is a member of the Board of Directors of the Lighthouse Foundation, a nonprofit charitable organization, and a member of the MRS Board of Directors.

\section{Board of Directors}

Griselda Bonilla (2020) is a senior technical staff member and senior manager of the Advanced Interconnect Technology Group at IBM T.J. Watson Research Center. She leads a cross-functional team involved in the integration, scaling, and optimization of semiconductor materials, on-chip interconnects, and processes for use in the next generation of chips and electronic devices. In this role, she has a proven track record of successfully taking research concepts from the laboratory to early production. Her work has been rewarded internally with several technical accomplishments, including a
Corporate Award, IBM's highest technical recognition, in 2016. Bonilla has participated in MRS as a member, at conferences as a presenter and invited speaker, and as an editor of symposium proceedings.

Li-Chyong Chen (2019) is the director of the Center for Condensed Matter Sciences at National Taiwan University (NTU), Taiwan. She also leads NTU's Advanced Materials Laboratory, where her program focuses on low-dimensional nanomaterials and related hybrids. She served as a symposium chair for the 2008 MRS Spring Meeting and the International Materials Research Congress/China-MRS 2008. She was a 2009 MRS Fall Meeting chair. From 2010 to 2011, Chen chaired the Pacific Rim Subcommittee under the MRS International Relations Committee. She was recognized as a MRS Fellow in 2010.

Matt Copel (2018) is a research staff member at the IBM T.J. Watson Research Center. He has made contributions to areas where electronic materials are critical to industrial applications, using expertise in structural characterization to guide development. He co-invented the technique of surfactant mediated epitaxy. He currently serves on the Penn State Materials Research Institute Industrial Advisory Board. He is a Fellow of the American Physical Society. He has served on the MRS New Publications Products Subcommittee (2011-2014) and has participated in several MRS task forces.

Paul S. Drzaic (2018) is senior manager for emerging display technology for Apple, Inc., where he and his group are responsible for the evaluation, development, and implementation of new display technologies. A common R\&D theme across Drzaic's career has been flexible displays and electronics and novel electro-optical effects. He served as a volume organizer for MRS Bulletin in 2004 and has served as chair of MRS Bulletin's Editorial Board from 2005 to 2015 . He was a symposium organizer for the first MRS symposium on flexible electronics in 2002 and served as a Meeting chair for the 2006 MRS Spring Meeting. He was awarded the MRS Woody Award in 2009.
Dawnielle Farrar-Gaines (2019) is a senior electrical and materials engineer at the Johns Hopkins University (JHU) Applied Physics Laboratory and a professor in the JHU School of Engineering. She is responsible for providing creative solutions to problems across disciplines, including nanomaterials, piezoelectric and multifunctional materials, sensors, microscopy, microelectronics, and packaging. Her research interests include micro/ nano systems, polymer materials, medical devices, and transducers. She received the MRS Woody Award in 2013, won first place in the Innovation in Materials Science (iMatSci) forum in 2014, and was chair of the MRS Women in Materials Science and Engineering Committee from 2011 to 2016.

Yury Gogotsi (2018) is the Charles T. and Ruth M. Bach Distinguished University Professor in the Department of Materials Science and Engineering at Drexel University. He also holds courtesy appointments in the Departments of Chemistry and Mechanical Engineering and Mechanics at Drexel University. He is the founding director of the A.J. Drexel Nanomaterials Institute. His current research interests focus on the chemistry of nanostructured carbons and carbides. $\mathrm{He}$ was a part of the team that discovered a new family of 2D carbides, nitrides, and carbonitrides of transition metals (MXenes). He has been active in MRS for more than 20 years. He has organized various MRS symposia and was selected for the Fred Kavli Distinguished Lectureship in Nanoscience in 2014. He was the founding advisor of the MRS Student Chapter at Drexel and served as chair of the MRS Student Chapters Subcommittee (2011-2015).

Claudia E. Gutiérrez-Wing (2019) is a researcher in the Department of Materials Technology at the Instituto Nacional de Investigaciones Nucleares (National Institute for Nuclear Research) in Mexico, where she founded a laboratory for the synthesis of nanomaterials in 1996. Her research is focused on the synthesis, characterization, and applications of nanomaterials. Of particular interest is the design of metallic nanoparticles 
and self-assembling processes, metallic nanowires, and nanocomposites for different applications under conventional and radiation exposed environments. Gutiérrez-Wing was a 2013 International Materials Research Congress co-chair, organizer of several symposia, and an editor for its proceedings. She served as the treasurer of the Sociedad Mexicana de Materiales from 2011 to 2012 and as vice president from 2013 to 2016.

Young-Chang Joo (2018) is a professor in the Department of Materials Science and Engineering at Seoul National University in South Korea since 1999. His recent research focuses on developing new pathways for synthesis of materials for energy devices based on nanoscale metallurgy. He has been involved in MRS since his graduate studies and has organized three symposia at MRS Meetings. He served as a Meeting chair for the 2008 MRS Fall Meeting and was a member of the MRS Program Development Subcommittee Tutorial Review Group.

Lincoln J. Lauhon (2019) is the associate chair and the director of graduate studies in the Department of Materials Science and Engineering at Northwestern University. His research interests include the physics, chemistry, and applications of nanostructured semiconducting materials and devices. He pioneered the use of atom probe tomography to analyze doping in semiconductor nanowires and probe the ultimate limits of composition control. He has been active in MRS for 20 years, beginning with the 1996 MRS Fall Meeting, and has organized several symposia. He has served on the MRS Program Development Subcommittee since 2011.

Paul McIntyre (2020) is the Rick and Melinda Reed Professor in the School of Engineering and department chair of materials science and engineering at Stanford University. He leads a research team that performs basic research on nanostructured inorganic materials for applications in electronics and energy technologies. He is best known for his work on metal oxide/semiconductor interfaces, ultrathin metal oxide films, atomic layer deposition, semiconductor nanowires, and materials for (photo)electrochemical energy transformations. McIntyre has been a member of MRS since attending his first Fall Meeting in 1989. He has served as a MRS symposia organizer and was a Meeting chair for the 2010 MRS Spring Meeting. He chaired the MRS Publications Committee from 2010 to 2013, and he has served as a principal editor of MRS Communications since its founding in 2011.

Christopher A. Schuh (2020) is the department head and the Danae and Vasilis Salapatas Professor of Metallurgy in the Department of Materials Science and Engineering at the Massachusetts Institute of Technology. His research focuses on metals, including their processing, microstructure, and mechanics. Much of his work is on the design and control of grain-boundary structure and chemistry in alloys, and he has commercialized a number of metals technologies from his research. He also currently serves as the coordinating editor of the Acta Materialia family of journals, and has held a number of roles within MRS over the past 15 years.

Rachel Segalman (2020) is the Kramer Chair Professor of Materials and Chemical Engineering and the department chair of chemical engineering at the University of California, Santa Barbara. Segalman's group works on controlling the structure and thermodynamics of functional polymers, including semiconducting and bioinspired polymers. Among other awards, Segalman received the 2015 Journal of Polymer Science Innovation Award and the 2012 Dillon Medal from the American Physical Society. She is also a Fellow of the American Physical Society, an Alfred P. Sloan Fellow, a Camille Dreyfus Teacher Scholar, and was named one of Technology Review's Top 35 Innovators under 35. She served as a Meeting chair for the 2013 MRS Spring Meeting and has organized symposia in 2006 and 2014.

Magaly Spector (2018) serves as the assistant to the president for strategic initiatives and professor in practice at The University of Texas at Dallas. She has pioneered a large number of new technologies and holds eight patents. In 2004, she was selected as a Bell Labs Fellow for her contributions in solid-state physics, II-V material for semiconductor lasers, GaAs, ICs, and quality and reliability of products used in high-speed optical transport systems for next-generation high bandwidth communication. She received the MRS Woody Award in 2013. She has also served as the MRS Diversity Subcommittee chair.

Molly M. Stevens (2019) is a professor in the Departments of Materials and Bioengineering and is a research director for biomedical materials science in the Institute of Biomedical Engineering at Imperial College London, UK. Her research program aims to create biomaterials with impact on regenerative medicine, tissue engineering, and biosensing. She is also co-director of the UK Regenerative Medicine Platform Hub and co-director of the UK's Interdisciplinary Research Centre, i-sense. She has organized several MRS symposia in the area of self-assembly and nanomaterials and served as a Meeting chair for the 2014 MRS Spring Meeting. She has served on the MRS Program Development Subcommittee.

Ehrenfried Zschech (2020) is department head for microelectronic materials and nanoanalysis at the Fraunhofer Institute for Ceramic Technologies and Systems, Germany. His responsibilities include multi-scale materials characterization and reliability engineering. He holds an adjunct professorship at the Faculty of Chemistry, University of Warsaw, Poland, as well as honorary professorships for nanomaterials at Brandenburg University of Technology and for nanoanalysis at Technische Universität Dresden, Germany. He has acted as a German Materials Research Society Board member and a Federation of the European Materials Societies (FEMS) Executive member. He served as FEMS president in 2012-2013. Zschech has been a member of the Steering Committee of The European Platform on Advanced Materials and Technologies since 2013, and an Operational Management Board member of the European Materials Characterization Council since 2016. 